\title{
Students' Perceptions of Flipped Classrooms, Gender, and Country Difference
}

Emad Ahmed Abu-Shanab, Qatar University, Qatar

https://orcid.org/0000-0002-2826-883X

\begin{abstract}
Information technology and the Internet has enabled faculty and educational institutions to implement new teaching methods to enrich the educational environment. The flipped classroom (FC) method changed the teaching practices and encouraged active learning. Using pre-class videos made the class time available for active discussions. This study utilized two samples to compare student perceptions on the challenges and benefits of such a method. The first sample included 200 students from a leading university in one of the Gulf Region countries, and the second sample included 114 students in Jordan. Results indicated a domination of higher means for the Jordanian sample, and the for males sample. Results partially supported the model for the Gulf university students and overall sample, but fully for the Jordanian sample. The strongest predictor of FC was perceived enjoyment and the weakest predictor was relative advantage. More results and discussion are reported at the end.
\end{abstract}

\section{KEYWORDS}

Country Differences, Flipped Classrooms, Gender Differences, Student Perceptions, Teaching Methods

\section{INTRODUCTION}

The major factors influencing education in the $21^{\text {st }}$ century revolved around technology and new teaching methods. The Internet applications and the influence of social media on our lives make it impossible to neglect such wave in all sectors and industries. The adoption of social media and new web 2.0 applications make it possible for many educators and scholars to adopt new methodologies and change their practices in teaching. The evolution in new technology use in education did not change our teaching practices only but opened doors for new innovative methods that would not be possible with the old traditional teaching environment.

Flipped classrooms is a new teaching method that depends on the previous setup of some classroom activities. The method utilizes the new technology available for teachers and students to open doors to a pre-interaction between the two and an open discussion before and during class time. In flipped classes, instructors use online-posted videos to replace face-to-face teaching. Students see the posted videos before class time and come to class equipped with the knowledge and skills acquired from these videos. The class time is utilized for effective discussion to emphasize creative and deep learning activities (Ollermann, Rolf, Greweling, \& Klaben, 2017).

The new available technologies, supported by social media apps, made it possible to implement such innovative method. The pillars of flipped classes depend on the availability of the Internet, and the availability of open platforms that support such decomposition of traditional classroom activities.

This article, originally published under IGI Global's copyright on October 1, 2020 will proceed with publication as an Open Access article starting on January 28, 2021 in the gold Open Access journal, International Journal of Web-Based Learning and Teaching Technologies (converted to gold Open Access January 1, 2021), and will be distributed under the terms of the Creative Commons Attribution License (http://creativecommons.org/licenses/by/4.0/) which permits unrestricted use, distribution, and production in any medium, provided the author of the original work and original publication source are properly credited. 
Furthermore, the method supports active learning and higher thinking skills and competencies (ArnoldGarza, 2014). Once students acquired the material, it is their responsibility to search and find needed extra resources and open their minds for new thinking ventures while in class time.

Most universities are keen on using flipped classes to equip their students with the needed competencies and make sure they acquire the planned learning outcomes. Still, many obstacles and challenges are reported in the literature that prevent universities from utilizing this method. The focus of this paper is to explore the factors influencing the adoption of flipped classrooms and the differences in students' perceptions accounted to country and gender influence. The study utilized more than one sample, using the same instrument and research model. The following section will review the literature related to flipped classrooms in an attempt to link the contributions of the method with our research objectives, followed by research method, data analysis, discussion and conclusions.

\section{BACKGROUND}

Teaching methods are depending more and more on technology use, where universities, faculty members, and students are exploring new available options. Flipped classes are used to focus the class time toward a discussion more than offering knowledge. In its basic form, teachers prepare the material using short video clips and upload them to the Internet (using a learning management system (LMS)). Students watch the videos and come to class for discussion. Such setup is changing the role of faculty members from knowledge providers to learning facilitators. The major definitions related to flipped classes revolves around shifting the management of the learning process from teachers to students. Such definition is considered the foundation of many reported ones that focused on making students the new knowledge producers rather than consumers (Cohen, 2016; Shu, 2015).

Online videos are the main tool for offering the material (Foldnes, 2016) where blended learning is used. The technique is used to optimize class time and change the role of students and teachers (Zhang, Dang \& Amer, 2016). Teachers are facilitators of the learning process, where they help students understand the material and answer their request for clarifications (Obradovich, Canuel, \& Duffy, 2015). Researchers emphasized the role of flipped classes in enhancing active learning and reducing the offering of material (Koo \& Panahi, 2016). The method catches the innovative activities in a course and stresses the role of students in managing their learning process (Bhagat, Chang, \& Chang, 2016).

The flipped classroom method incorporates many principles and techniques. The reported research varied in such direction and included no agreed upon structure of the method. Table 1 reports such principles and summarizes the structure of the method and the references used to report them.

\subsection{Advantages and Disadvantages of Flipped Classrooms}

Reported research supports the role of flipped classes in enhancing active learning, where faculty members work together with students in solving assignments and answering their questions. The available time for the class is devoted to such active discussions (Davis, 2016). The second advantage of the method is the open domain for learning/teaching resources, where the material needed for any course is offered for students on LMSs and provide the foundation for learning. Still, with this bond to the Internet, extra available resources are used to support course material (Doi, 2016). The author also supports the notion of empowering students to be active learners as they surf the Internet to acquire more resources and come to class equipped and ready for active discussion.

The strength of the flipped classes' method stems from addressing the learning needs of students (Moran \& Milsom, 2015). The customization of the teaching process is one of the strengths of flipped classrooms, where students can review the material based on their personal competencies and level of achievement (Hsu, Chen, Chang, \& Hu, 2016). Students can see the videos more than once and prepare for in-class activities (assessment or discussion). On the other hand, they can focus on their deficiencies or strengths, and build a customized learning model that emphasizes synthesis, evaluation 
Table 1. Structure and principles of flipped classrooms

\begin{tabular}{|c|c|c|}
\hline$\#$ & Principles & Source \\
\hline 1 & Change the role of students and teachers & $\begin{array}{l}\text { Obradovich et al. (2015); Cohen (2016); } \\
\text { Shu (2015) }\end{array}$ \\
\hline 2 & $\begin{array}{l}\text { Use class time for discussion, clarifications, and feedback on } \\
\text { assessment and activities }\end{array}$ & Foldnes (2016); Gubbiyappa et al. (2016) \\
\hline 3 & $\begin{array}{l}\text { Utilization of video clips (multimedia and other types of } \\
\text { technology), to improve learning before class. Technology is not } \\
\text { sophisticated or specialized }\end{array}$ & $\begin{array}{l}\text { Rotellar (2016); Bhagat et al. (2016); Zhang } \\
\text { \& Xu (2015); Hotle \& Garrow (2016) }\end{array}$ \\
\hline 4 & $\begin{array}{l}\text { Addressing individual differences (through rehearsing and replay } \\
\text { of video) }\end{array}$ & Bhagat et al. (2016); Rotellar (2016) \\
\hline 5 & $\begin{array}{l}\text { Offer a mechanism for assessment; prepare students for final } \\
\text { assessment }\end{array}$ & Rotellar (2016); Gubbiyappa et al. (2016) \\
\hline 6 & Bridge the gap between in-class and out-class activities & Tolks et al. (2016); Rotellar (2016) \\
\hline 7 & $\begin{array}{l}\text { Build a learning community and enhance active learning (more } \\
\text { cooperative, interactive and fun) }\end{array}$ & $\begin{array}{l}\text { Koo \& Panahi, (2016); Rotellar (2016); } \\
\text { Bhagat et al. (2016); Cohen (2016); } \\
\text { Marsono (2016) }\end{array}$ \\
\hline 8 & $\begin{array}{l}\text { Increase students' innovative methods like problem solving skills, } \\
\text { creativity and research skills }\end{array}$ & $\begin{array}{l}\text { Baytiyeh (2017); Sivapalan (2017); Meyers } \\
\text { (2016); Al-Zahrani (2015) }\end{array}$ \\
\hline
\end{tabular}

and understanding of the material (Gilboy, Heinerichs, \& Pazzaglia, 2015). Finally, students can address their weaknesses by utilizing class time instead of being exposed to the course material for the first time.

From a teacher's perspective, flipped classes offer an opportunity to expand the material and interact with students toward a more focused dimensions rather than offering a rigid material that might not be learner-centered (Moran \& Milsom, 2015). The second advantage is the change in roles that makes teachers facilitators rather than the owners of the content (Cohen, 2016; Shu, 2015). Finally, teachers are also exposed to new ideas and concepts based on the sources students use when preparing for class. The offering of the course material through a traditional setup makes the course structured and standardized, where teachers are exposed to the same experience each semester. Flipped classes offer an opportunity to interact with students and open venues for new concepts that attract student, address their questions, and correct any errors or misconceptions related to course material. Through this procedure, higher cognitive learning practices support the learning process (Davis, 2016; Nederveld \& Berge, 2014).

Although flipped classrooms are well supported in the literature, many issues are still reported that challenge their use and hinder their adoption. Researchers stressed the importance of multimedia and the high-quality videos (Zainuddin \& Attaran, 2016). Such issue forces the use of short videos that would require less effort and simple technical requirements. Based on that, the needed infrastructure is one of the major challenges that prevents many universities and faculty members from using such method. When we talk about technological infrastructure, we mean videotaping studios to produce videos with an acceptable resolution and a manageable size. In addition, a researcher reported that absent students can see the videos and recover what they missed from the course material (Doi, 2016), which might encourage students not to attend the class and depend on posted videos.

The major downside of flipped classes is student attitude towards the method. If students do not buy into the process and do not put the effort into seeing the material and preparing for the class, the class time may become a negative pressure, where students may feel they are lost. Based on such conclusion, this study tries to investigate the major factors that influence students' decision to embrace the method and benefit from its advantages. 


\subsection{Perspectives on Adoption}

Students perceive new teaching methods positively because of the use of technology and the flexibility they offer. Introvert students feel that the exposure to material before class will encourage them to participate in class discussion more (Koo \& Panahi, 2016). Still, increasing the portion of discussion and class interaction over the traditional style of lecturing might yield negative perceptions regarding the use of the method. As claimed by previous researchers, the method is known for its customization of teaching toward individual students' learning styles (Bhagat et al., 2016; Rotellar, 2016).

The second perceptional issue is the enjoyment contained within the activities of flipped classrooms. Researchers reported that students like to work within small groups, enjoy the discussions generated in classrooms, and like using applications that support the method like Google apps and diverse social media (Jeong et al., 2016; Alquraan et al., 2017). Such details will encourage students to be active learners and participants in the method (Huang \& Hong, 2015). On the contrary, the method might put high pressures on students with different learning styles. Not all students like to work in groups, and some cultural and societal issues might hinder the adoption of such method (Furumo, Hennessey \& Abu-Shanab, 2011).

Technology and social media are significantly influencing students' performance (Abu-Shanab, \& Al-Tarawneh, 2015). Researchers indicated that flipped classes are more suitable for high performers than low performers (Beatty \& Albert, 2016). The authors report that the reasons behind such result is the independent style of high performers, where they prefer to prepare for classes before class time and come to acquire the needed competencies. Other researchers reported that students were more satisfied with the method (Koo \& Panahi, 2016), and yielded higher grades when using flipped classes (Beatty \& Albert, 2016). Flipped classrooms, if not performed successfully, will result in frustration and isolation for low performance students. Such issue will make the method risky and will result in negative students' perceptions. The same previously mentioned study by Koo and Panahi (2016) reports that some students were not satisfied with the overall experience of the teaching method. The major reasons reported were the extra workload and the long time spent watching the videos. Beatty and Albert (2016) reported other reasons for such dissatisfaction and are related to language weaknesses, personality type, cognitive processing capabilities, and speaking and listing abilities.

Another positive perception stems from the support provided through videos to students when they study for quizzes/exams or when solving their assignments (Long, Logan \& Waugh, 2016). Compared to reading the textbook, watching videos is more interesting. The authors claim that students prefer videos built by their own instructor, where it relates to their specific context, assignments, and exams. Another positive perception is the improved communication and collaboration with their classmates and instructor built through the in-depth discussion in class (Al-Zahrani, 2015). The literature reports this issue more, where the social influence of flipped classes encourages weak students to express their opinions within groups and in many cases improves their performance (Huang et al., 2014).

\subsection{Gender and Country Influence}

The technology adoption research includes many studies on gender's moderating effect, where females and males respond differently to the use of technology (Tan \& Ooi, 2018). Researchers looked at this factor as a moderator to relationships within the technology acceptance domain (Tarhini et al, 2014), while others considered it a direct predictor (Li et al., 2008). Males and females use different cognitive schemes in their decision-taking process and thus adopt technology in a different manner (Venkatesh $\&$ Morris, 2000). Focusing more on our related constructs, gender was a significant moderator to the relationship between relative advantage and intention to use the technology (Mandari \& Chong, 2018).

In another study related to smart phone use, Ameen et al. (2018) concluded that both females and males are aware of the importance of technology. The study is similar to our study in comparing two samples (Gulf Cooperation Council (GCC) country and Jordan), but implemented on smart phones technology. The results confirmed gender role as a significant moderator for enjoyment and relative advantage and their relationship to intentions for the United Arab Emirates (UAE) sample (but not 
for the Jordanian sample). The previously mentioned study by Tan and Ooi (2018) could not find any significant moderation for all relationships proposed in the model (Unified Theory of Acceptance and Use of Technology 2 (UTAUT2)) except the trust and intention to use (ITU) relationship. Such results support the conflicting results reported in previous research. Finally, in the educational area, some studies failed to support the influence of gender as a moderator (Wang et. al, 2009).

Country influence on technology adoption domain was explore under two major direction: First, country as a moderator, where it was treated like gender or age. The second direction is to compare two samples from two countries (or more), where differences are related to national culture, country infrastructure, and awareness. Ameen et al (2018) used cultural differences attributed to country as a predictor to smart phone adoption. Their results as described previously emphasized the difference between the Jordanian sample and the UAE one.

Another study also compared the adoption of two samples from Estonia and Turkey and focusing on e-learning (Güllü et al., 2016). The study extended the technology acceptance model and compared the perceptions of lecturers from six universities from the two countries. Results indicated the Estonian sample showed more satisfaction with e-learning systems, where the Turkish sample indicated the country's poor infrastructure, outdated systems, absence of vision, and policy issues. The study also looked into differences among universities sampled, which is outside the scope of our study.

In a similar study, Nyagorme (2010) compared the perceptions of two samples from Ghana and Kenya. The study utilized the Theory of Reasoned Actions (TRA) and the Diffusion of Innovation theory (DOI). The author categorized the factors that would influence adoption into four areas: managerial, perceived e-learning attributes, end-user factors, and institutional factors. Results indicated that the level of e-learning adoption was low in both countries. Reasons for such level are the lack of top management commitment, negative attitudes of lecturers, lack of fund, and low self-efficacy of learners.

\subsection{Research Model}

In summary, we adopt the following definition of flipped classroom as a teaching method that utilizes the time outside the class to prepare students for the discussion in the classroom using video clips posted on the Internet or the university LMS. Such definition implies a change in roles for both students and teachers. Teachers are facilitators of the learning process and give feedback and support to students, where students own the content, the learning style and control the learning process. Being a new method, many universities in developing countries encourage using such methods.

The previous literature also indicated that relative advantage and enjoyment are major predictors of FC adoption, (where such direction is a subset of the UTAUT 2 (Unified Theory of Acceptance and Use of Technology). The previous literature review concluded to four factors influencing the adoption of flipped classrooms. The four factors are the relative advantage of FC (RA), perceived enjoyment (PE), collaboration gains (CG), and perceived creativity (PC). Based on this, we formulated the research model shown in Figure 1 below and the following set of hypotheses are assumed (for the overall sample). Similarly, we adopted the following definitions of variables based on previous research and proposed by the author (modified for the purpose of this study).

Relative advantage of using FC would be "the degree to which FC method is perceived as being better than the previous methods it supersedes" (Rogers, 2003; Mndzebele, 2013; Mairura, 2016)

Perceived enjoyment of using FC is the "degree to which the user deems FC teaching method as a fun experience regardless of outcome" (Davis et al., 1992; El Shamy \& Hassanein, 2017; Lai \& Ahmad, 2014).

Collaboration gains is defined as "the gains generated from using FC teaching methods for students and instructors" (proposed by the authors).

Perceived creativity is defined as "the degree that FC method can increase the willingness of an individual to try out any new technology or application" (adapted from personal innovativeness but 
modified to show FC influence. The definition of personal innovativeness is adopted from the work of Agarwal and Parasad (1998) and Rogers (2003).

FC adoption is defined as "the degree students adopt FC method and plan/intend/expect to use in the future". The definition stems from the technology adoption literature and used as a surrogate of use behavior (Venkatesh et al., 2003; Venkatesh et al., 2012).

H1: Relative advantage will have a positive and significant influence on students' adoption of flipped classrooms.

H2: Collaboration gains will have a positive and significant influence on students' adoption of flipped classrooms.

H3: Perceived enjoyment will have a positive and significant influence on students' adoption of flipped classrooms.

H4: Perceived Creativity will have a positive and significant influence on students' adoption of flipped classrooms.

Figure 1. Research model

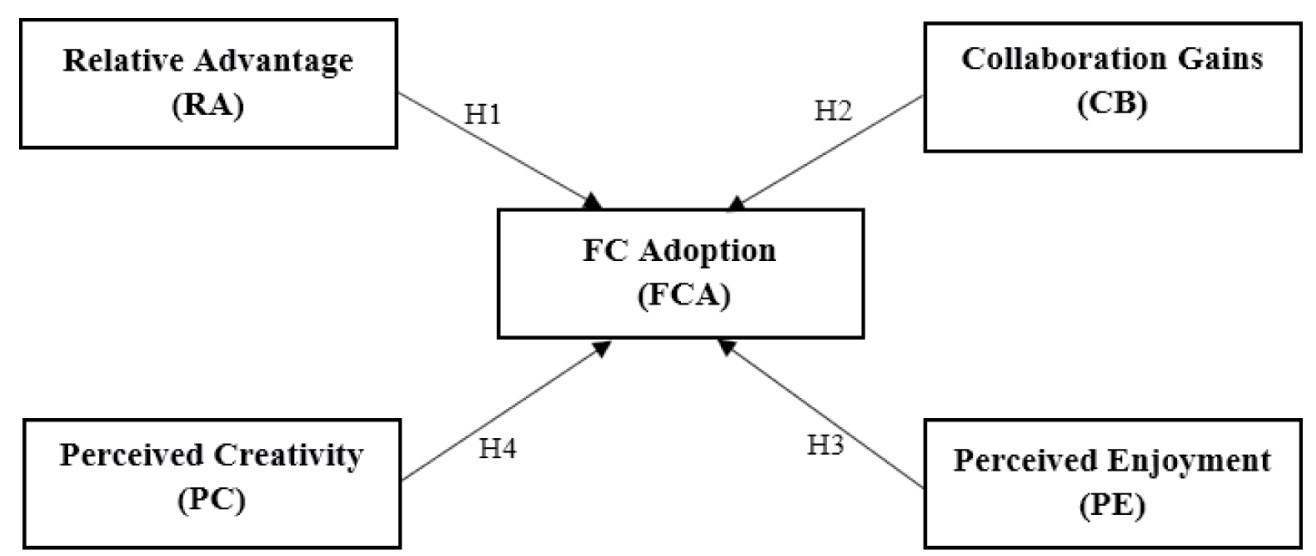

\section{RESEARCH METHOD}

Research related to technology adoption reports differences related to gender, where females reacted differently to technology adoption when compared to males. FC is not different, the more you emphasize the technology content, the more gender becomes a critical factor. The differences in gender are also related to country, where some traditions and norms prohibit mixing female and male classes. Such issue might stress the importance of technology in bridging this obstacle. In this paper and this context, we try to test the influence of both factors in an attempt to see if they are significant, where future studies can enrich the method with extra cultural differences that interact with gender and technology use.

This study focused on comparing the results of two samples drawn in two different countries to understand the perceptions of students and to see if the results of the tested model differ between the two samples. The study will use two statistical techniques: the first is regression analysis to try to estimate the prediction model for both samples. The second technique is an ANOVA test that compares the difference in means for all items and variables of the two samples. 


\subsection{Research Instrument}

The first step was to build the instrument to be used for data collection. Flipped classrooms (FCs) is a new method in education, and the research related to its influence in the Arab world is scarce. Based on that, a survey including 25 items covering five dimensions related to the teaching method obtained from the literature review. Three faculty members who use FCs reviewed the survey instrument, made a few comments on some items, and amended the initial survey. The survey included four sections: the first introduced the research context and some guidelines for respondents; the second section described FCs to give students some insights as to the details of the method; the third section required students to report their gender, age, and educational level; the third section also included two questions related to FC awareness and its use; and the fourth section included 25 items measuring the five dimensions of our research model.

The survey items utilized a Likert scale with 5 points: 1 represents a total disagreement and 5 represents a total agreement. The survey included 6 items measuring relative advantage, 5 items measuring perceived enjoyment, 6 items measuring perceived creativity, 4 items measuring collaboration gains, and 4 items measuring FC adoption. The survey was built in Arabic language and targeted university students.

\subsection{Sample and Sampling Process}

This study utilized two different samples, the first in a leading public university in one of the GCC countries, and the second in a public university in Jordan. The researcher collected data from students registered in eight classes in the College of Business and Economics in the university. Data collection was done on a voluntary basis and in class time. 200 surveys were collected, where students filled in the survey without any incentive provided (extra credit). The selection of faculty members was also done on a voluntary basis. We collected the data from November 26 to December 7, 2017. The second sample was collected online based on a course offered for students in a public university in Jordan. The course offering is similar to the Qatari sample (face-to-face teaching), where the faculty member who volunteered to sample his students used FC as a method of helping students to improve their understanding of the material. The sample targeted an online group registered for a computer science course, where the instructor invited them voluntarily to fill in the survey online (Group size 600 students enrolled in multiple classes). The course utilized video clips to support the learning process, where the description of the FC method served the purpose of linking the method to the subjects so they could respond to the questions properly. The total online usable surveys were (114). The collected data was keyed into a spreadsheet application and transferred into SPSS for data analysis. The demographics of data are shown in Table 2.

The distribution of students in the College of Business and Economics in the university shifts towards more female students (65\%), where some students earned a diploma and extended their study to undergraduate. Their distribution might seem illogical based on students' perception of their status. Some considered themselves as undergraduate and some considered themselves as having earned a high school diploma and pursuing an undergraduate degree. Finally, we can see that $75.5 \%$ know about FC, but only two thirds experienced such method during their study in Qatar University (QU).

The Gulf sample is larger than the Jordanian sample, which might be an indication of the usage of the method. The Gulf sample included a female percentage larger than the Jordanian one, older respondents, and a distorted degree of education (as mentioned previously). Based on the flipped classroom awareness, the Gulf sample outperformed the Jordanian one, but reported less experience in it. The reason behind such result might be the popularity of the method among the administration of the University. As for the Jordanian sample, we introduced the method to an online group, which made their responses more favorable toward the method and their experience using it. 
Table 2. Data demographics

\begin{tabular}{|c|c|c|c|c|c|c|}
\hline Demographic Factor & \multicolumn{2}{|c|}{ Gulf Sample } & \multicolumn{2}{|c|}{ Jordanian Sample } & \multicolumn{2}{|c|}{ Total Sample } \\
\hline Gender & Freq. & $\%$ & Freq. & $\%$ & Freq. & $\%$ \\
\hline Male & 43 & 21.5 & 52 & 45.6 & 95 & $30 \%$ \\
\hline Female & 153 & 76.5 & 61 & 53.5 & 214 & $68 \%$ \\
\hline Not reported & 4 & 2.0 & 1 & 0.9 & 5 & $2 \%$ \\
\hline Age & Freq. & $\%$ & Freq. & $\%$ & Freq. & $\%$ \\
\hline $18-22$ years & 131 & 65.5 & 109 & 95.6 & 240 & $76 \%$ \\
\hline $22-30$ years & 63 & 31.5 & 4 & 3.5 & 67 & $21 \%$ \\
\hline More than 30 years & 6 & 3.0 & 1 & 0.9 & 7 & $2 \%$ \\
\hline Education & Freq. & $\%$ & Freq. & $\%$ & Freq. & $\%$ \\
\hline High school & 33 & 16.5 & 2 & 1.8 & 35 & $11 \%$ \\
\hline Diploma & 27 & 13.5 & 0 & 0 & 27 & $9 \%$ \\
\hline Undergraduate & 122 & 61.0 & 112 & 98.2 & 234 & $75 \%$ \\
\hline Not reported & 18 & 9.0 & 0 & 0 & 18 & $6 \%$ \\
\hline Previous awareness of $\mathrm{FC}$ & Freq. & $\%$ & Freq. & $\%$ & Freq. & $\%$ \\
\hline Yes & 151 & 75.5 & 67 & 58.8 & 218 & $69 \%$ \\
\hline No & 49 & 24.5 & 47 & 41.2 & 96 & $31 \%$ \\
\hline Previous experience in FC & Freq. & $\%$ & Freq. & $\%$ & Freq. & $\%$ \\
\hline Yes & 99 & 49.5 & 67 & 58.8 & 166 & $53 \%$ \\
\hline No & 98 & 49.0 & 47 & 41.2 & 145 & $46 \%$ \\
\hline Not reported & 2 & 1.0 & 0 & 0 & 2 & $1 \%$ \\
\hline Total & 200 & 100 & 114 & 100 & 314 & $100 \%$ \\
\hline
\end{tabular}

\section{DATA ANALYSIS AND DISCUSSION}

This study tried to explore the differences between two major demographic factors: Gender and Culture. The other sampled demographic factors (education and age) violated the sample size for conducting an analysis of variance (ANOVA) test. The vast majority of sample members concentrated on one category and in just one of the samples (i.e. undergraduate degree and first age category were unbalanced in the Jordanian sample.) In addition, students' perceptions in the Gulf sample regarding their education degree made the factor biased and lost its validity for analysis. The purpose of this study was to compare the differences between Gulf and Jordanian perceptions. To corroborate our findings we also conducted analyses based on gender. The following two sections depicts the results and discussion.

\subsection{Gulf vs. Jordanian Perceptions}

The tests conducted within a cultural context were focused on comparing means and the results of the two research models. We tested our model for predicting the adoption of flipped classrooms with the objective of estimating the differences between the Gulf and Jordanian samples. The model assumed that the adoption of flipped classrooms would be influenced by four factors: relative advantage of FC (RA), perceived enjoyment (PE), collaboration gains (CG), and perceived creativity (PC). All 
Table 3. Means and standard deviations of the major variables

\begin{tabular}{|l|l|l|l|l|l|l|l|}
\hline \multirow{2}{*}{ Constructs } & \multicolumn{2}{|c|}{ Gulf Sample } & \multicolumn{2}{c|}{ Jordan Sample } & \multicolumn{2}{c|}{ All Sample } & $\begin{array}{c}\text { Cronbach's } \\
\text { Alpha* }\end{array}$ \\
\cline { 2 - 8 } & Mean & Std.Dev. & Mean & Std.Dev. & Mean & Std.Dev. & 0.877 \\
\hline Relative Advantage (RA) & 3.751 & 0.966 & $3.936^{* *}$ & 0.587 & 3.818 & 0.852 & 0.754 \\
\hline Perceived Enjoyment (PE) & 3.680 & 0.880 & $3.854^{* *}$ & 0.558 & 3.743 & 0.782 & 0.754 \\
\hline Perceived Creativity (PC) & 3.485 & 0.978 & $3.787^{* *}$ & 0.634 & 3.593 & 0.879 & 0.926 \\
\hline Collaboration Gains (CG) & 3.298 & 0.980 & $3.452^{* *}$ & 0.811 & 3.353 & 0.923 & 0.881 \\
\hline FC Adoption (FCA) & 3.158 & 1.166 & $3.708^{* *}$ & 0.882 & 3.357 & 1.103 & 0.906 \\
\hline
\end{tabular}

*Data for all sample

${ }^{* *}$ Highlighted figures are the highest

factors are reported based on students' perception of the method. This means that the results depend on students' reported perceptions more than objective measures.

The first step is to estimate the items and variables means based on the average estimation of all items constituting the variable. Such estimation will give us an idea about the variables and how they are perceived by respondents. Three measures are estimated in this study: a measure for the Gulf sample, a measure for the Jordanian sample, and a measure for the overall sample. Appendix A includes all the results of the means. Results were dominated by higher means from the Jordanian Students. The item means might not be significantly different, but still such domination across all survey items represents a tentative conclusion that Jordanian students were influenced more by the videos posted by the course instructor and this their perceptions are much improved. Such conclusion will be tested later by the ANOVA estimates.

Table 3 reports the results of overall means estimations of the variables. It is important to comment on the values of Cronbach's alpha reported in Table 3 (the last column on the right). The values are estimated for all the sample, where all values are at recommended levels $(>0.8)$ except for Enjoyment with an acceptable level (0.6-0.8) (Hair et al., 1998). As for the means, they are also similar to the items' level, where all major variables showed higher means for the Jordanian sample.

The reported results in Appendixes A and B and in Table 3 indicate higher means for the Jordanian sample as compared to the Gulf sample. Such result provides important insights and throws away the possibility of chance. Having all means of the Jordanian sample higher than the Gulf sample invites for further investigation to reach a solid conclusion of one of two possibilities. The first, the Gulf sample experienced the method and are not supportive of using it. The second possibility, Jordanians utilized the videos voluntarily as they were helpful in understanding the material.

Stepping into the relational tests, we estimated the Pearson's correlations among variables (Shown in Table 4) using the entire sample. Such step is important for two different reasons. First, we need a confirmation of the relationship between adoption and the independent variables. The results shown in Table 4 indicate that all selected variables are suitable and significantly predict the adoption of the flipped classrooms method when entered in the prediction model alone (Last row of Table 4). The second purpose is to test for multicollinearity, where excessively high correlations between the independent variables indicate such issue. Values higher than 0.85 would be considered by many statistical resources as a commonality between variables (Hair et al. 1998).

The second step on the variable level is to conduct an ANOVA test between the two samples. The results indicated that two variables were different according to country differences: Perceived creativity and adoption. Still, it is important to comment on the $\mathrm{F}$ values associated with relative advantage and enjoyment, where both were close to 0.05 (the recommended threshold in social sciences for an error rate). Such result fairly supports the influence of culture/country in adopting such method. It is 
Table 4. Pearson's Correlation Matrix (overall sample)

\begin{tabular}{|l|l|l|l|l|l|}
\hline \multicolumn{1}{|c|}{ Construct } & \multicolumn{1}{|c|}{ FCB } & \multicolumn{1}{|c|}{ FCE } & \multicolumn{1}{|c|}{ FCID } & \multicolumn{1}{|c|}{ FCSI } & FCA \\
\hline Relative Advantage (RA) & 1 & & & & \\
\hline Perceived Enjoyment (PE) & $0.746^{* *}$ & 1 & & & \\
\hline Perceived Creativity (PC) & $0.718^{* *}$ & $0.735^{* *}$ & 1 & & \\
\hline Collaboration Gains (CG) & $0.519^{* *}$ & $0.496^{* *}$ & $0.589^{* *}$ & 1 & \\
\hline FC Adoption (FCA) & $0.641^{* *}$ & $0.698^{* *}$ & $0.700^{* *}$ & $0.563^{* *}$ & 1 \\
\hline
\end{tabular}

${ }^{* *}$ Correlation is significant at the 0.01 level (2-tailed).

also important to remind readers that the means of the Jordanian sample are higher on all variables. Table 5 shows the results and also the gender results (will be discussed later).

Following to the ANOVA test conducted to compare means, a regression analysis was conducted. The test was conducted three times, the first using the Gulf sample, the second using the Jordanian sample, and finally the total sample. The first test yielded a significant prediction of adoption with an $\mathrm{R}^{2}=0.621$ (Adjusted $\mathrm{R}^{2}=0.613, \mathrm{~F}_{4 / 194}=79.5 \mathrm{p}<0.001$ ). The second test (Jordanian sample) yielded an $\mathrm{R}^{2}=0.494$ (Adjusted $\mathrm{R}^{2}=0.476, \mathrm{~F}_{4 / 109}=26.6, \mathrm{p}<0.001$ ). Finally, the overall sample yielded also a significant prediction with an $\mathrm{R}^{2}=0.592$ (Adjusted $\mathrm{R}^{2}=0.586, \mathrm{~F}_{4 / 309}, \mathrm{p}<0.001$ ). Table 6 shows a summary of the first two tests, and Table 7 shows the coefficient table for the whole sample.

The prediction was the highest for the Gulf sample. The reason for such result is the variety of perceptions, which followed the levels of adoption, thus yielding higher prediction (62\%). In addition, the Gulf sample was larger, which might have influenced the results. Even though the two samples are more than 100, which supports the generalizability of results, still the larger the sample,

Table 5. ANOVA results comparing the means of the major variable

\begin{tabular}{|l|l|l|l|l|}
\hline \multirow{2}{*}{ Construct } & \multicolumn{2}{c|}{ Country Test } & \multicolumn{2}{c|}{ Gender Test } \\
\cline { 2 - 5 } & \multicolumn{1}{|c|}{ F } & \multicolumn{1}{c|}{ Sig. } & \multicolumn{1}{c|}{ F } & \multicolumn{1}{c|}{ Sig. } \\
\hline Relative Advantage (RA) & 3.443 & 0.064 & 4.373 & 0.037 \\
\hline Perceived Enjoyment (PE) & 3.653 & 0.057 & 3.075 & 0.081 \\
\hline Perceived Creativity (PC) & 8.905 & 0.003 & 10.213 & 0.002 \\
\hline Collaboration Gains (CG) & 2.070 & 0.151 & 8.173 & 0.005 \\
\hline FC Adoption (FCA) & 19.172 & 0.000 & 11.849 & 0.001 \\
\hline
\end{tabular}

Table 6. Coefficient table of regression (Gulf vs. Jordanian sample)

\begin{tabular}{|l|l|l|l|l|l|l|}
\hline \multirow{2}{*}{ Constructs } & \multicolumn{3}{c|}{ Gulf Sample } & \multicolumn{3}{c|}{ Jordanian Sample } \\
\cline { 2 - 7 } & \multicolumn{1}{|c|}{ Beta } & \multicolumn{1}{c|}{ t } & \multicolumn{1}{c|}{ Sig. } & \multicolumn{1}{c|}{ Beta } & \multicolumn{1}{c|}{ Sig. } \\
\hline (Constant) & & -3.343 & 0.001 & & -2.317 & 0.022 \\
\hline Relative Advantage (RA) & 0.061 & 0.799 & 0.425 & 0.209 & 2.241 & 0.027 \\
\hline Perceived Enjoyment (PE) & 0.371 & 4.669 & 0.000 & 0.267 & 2.993 & 0.003 \\
\hline Perceived Creativity (PC) & 0.287 & 3.585 & 0.000 & 0.202 & 2.143 & 0.034 \\
\hline Collaboration Gains (CG) & 0.167 & 2.801 & 0.006 & 0.238 & 3.198 & 0.002 \\
\hline
\end{tabular}


Table 7. Coefficient table of the overall sample

\begin{tabular}{|l|l|l|l|l|l|}
\hline \multirow{2}{*}{ Constructs } & \multicolumn{2}{|c|}{ Unstandardized Coefficients } & \multicolumn{1}{c|}{$\begin{array}{c}\text { Standardized } \\
\text { Beta }\end{array}$} & \multicolumn{1}{c|}{ S } & Sig. \\
\cline { 2 - 3 } & \multicolumn{1}{|c|}{ B } & \multicolumn{1}{|c|}{ Std. Error } & & -4.136 & 0.000 \\
\hline (Constant) & -0.863 & 0.209 & & 1.737 & 0.083 \\
\hline Relative Advantage (RA) & 0.134 & 0.077 & 0.103 & 5.377 & 0.000 \\
\hline Perceived Enjoyment (PE) & 0.459 & 0.085 & 0.325 & 4.565 & 0.000 \\
\hline Perceived Creativity (PC) & 0.350 & 0.077 & 0.279 & 4.025 & 0.000 \\
\hline Collaboration Gains (CG) & 0.220 & 0.055 & 0.184 & & \\
\hline
\end{tabular}

the more valid and significant the results are. The prediction for all tests is considered moderate and high when evaluating the power impact of each coefficient of determination (Cohen \& Cohen, 1983). Based on the results of the three tests, we can conclude that only the relative advantage of flipped classrooms is not influencing the prediction. This is based on the Gulf sample and its influence on the total sample. Finally, the strongest predictor among all independent variables used was perceived enjoyment (across all samples).

\subsection{Gender Differences}

Similar to the tests conducted between the Gulf and Jordanian samples, the same was done for gender factor. The first test compared the differences between males and females on the items level. The balance between the two sample sizes enabled us to conduct the ANOVA test. The sample included 214 females and 95 males, which is aligned with the population of both universities in The Gulf region and Jordan. Appendix C includes item estimates based on gender, which indicates a dominance of higher values for means associated with males. Such finding indicates that males perceived relative advantage, enjoyment, creativity, and collaboration gains as higher in the context of flipped classrooms. In addition, males reported higher adoption rates than females.

The results of the ANOVA test (shown in Appendix B, for both country and gender analysis) indicate a higher number of items showing differences than our previous country level analysis. It is obvious that significant differences are witnessed in the sample based on gender analysis. Only 8 means were not different as compared to 17 items which yielded significant differences. Adoption, collaboration gains and creativity included discriminating items except for one item (Perceived Creativity \# 2). The other factors did not show a dominant pattern for differences. Such result reveals that males and females have different perceptions regarding these variables. It is also reasonable to conclude that gender is a stronger discriminator with respect to flipped classroom adoption than country. Based on the experience of the author, females show more commitment than females, which again encourages more research to test for gender influence on adopting new teaching methods.

The previously reported Table 6 shows the ANOVA test on the variable level. Results indicate a stronger influence of gender than country, where all variable means were significantly different except for enjoyment. Again, male estimated means were higher on all variables when compared to female means. It looks like females and males are similar with their enjoyment, but yield significant differences based on FC adoption followed by creativity, collaboration gains, and relative advantage, respectively. In addition, both perceived creativity and FC adoption were similar, and gender differentiated relative advantage and collaboration gains.

The last step in the analysis is to explore the regression analysis on both male and female samples. The regression test was conducted two times, the first using the males sample, and the second using the females sample. The first test yielded a significant prediction with an $\mathrm{R}^{2}=0.590$ (Adjusted $\mathrm{R}^{2}$ $=0.572, \mathrm{~F}_{4 / 90}=13.66, \mathrm{p}<0.001$ ). The second test (female sample) yielded an $\mathrm{R}^{2}=0.592$ (Adjusted $\left.\mathrm{R}^{2}=0.584, \mathrm{~F}_{4 / 209}=75.86, \mathrm{p}<0.001\right)$. Finally, the overall sample test was conducted in the country 
analysis and yielded significant prediction with an $\mathrm{R}^{2}=0.592$ (Adjusted $\mathrm{R}^{2}=0.586, \mathrm{~F}_{4 / 309}, \mathrm{p}<0.001$ ). Table 8 shows the coefficient table results of the two sub-samples, and Table 7 (previously reported) shows the coefficient table of the overall sample. It is noticeable that the coefficient of determination is nearly similar in both cases and it shows that the strength of prediction of both samples is similar.

Table 8. Coefficient table of regression (male vs. female's samples)

\begin{tabular}{|l|l|l|l|l|l|l|}
\hline \multirow{2}{*}{ Constructs } & \multicolumn{3}{c|}{ Males Sample } & \multicolumn{3}{c|}{ Females Sample } \\
\cline { 2 - 7 } & Beta & \multicolumn{1}{|c|}{ t } & Sig. & Beta & \multicolumn{1}{c|}{ t } & Sig. \\
\hline (Constant) & & -2.132 & 0.036 & & -3.519 & 0.001 \\
\hline Relative Advantage (RA) & 0.206 & 1.923 & 0.058 & 0.084 & 1.142 & 0.255 \\
\hline Perceived Enjoyment (PE) & 0.129 & 1.195 & 0.235 & 0.397 & 5.349 & 0.000 \\
\hline Perceived Creativity (PC) & 0.278 & 2.628 & 0.010 & 0.276 & 3.669 & 0.000 \\
\hline Collaboration Gains (CG) & 0.318 & 3.996 & 0.000 & 0.113 & 1.991 & 0.048 \\
\hline
\end{tabular}

The results shown in Table 8 indicate that, even though the two samples were similar in prediction value ( 0.590 vs. 0.592$)$, a different beta value for the variables is estimated. The overall prediction is similar, but the details of contributing variables are not. The males sample showed a significant prediction for perceived creativity and collaboration gains, but the females sample showed an extra contribution for perceived enjoyment. On both sides, flipped classroom relative advantage did not reveal a significant prediction, but was close in the case of males. The strongest predictor of adoption was collaboration gains for the males' sample, enjoyment for the females' sample, and enjoyment for the overall sample.

\section{CONCLUSION AND FUTURE WORK}

This study tried to explore the differences between two samples drawn from a university in The Gulf region, and a Jordanian university. The collected data focused on using flipped classrooms to explore how students perceived the relative advantage, perceived enjoyment, perceived creativity, and collaboration gains of the method and how these factors influence students' adoption of the method. We utilized regression analysis and ANOVA tests to answer all our enquiries. The sample collected in both countries enabled us to conduct statistical analysis on two major factors: country and gender. Other demographic categories were limited with severe differences in sample size.

The results indicated that the instrument used is reliable on all variables (based on Cronbach's alpha values). The country analysis showed a superiority of Jordanian means of variables and even items used. Higher means of items and variables indicate a higher appreciation of method and tendency to adopt it. On the other hand, only perceived creativity and FC adoption showed significant differences in means. Regression tests indicated a higher prediction by the Gulf sample than the Jordanian one with a substantial difference in $\mathrm{R}^{2}$. This result supports the findings of Ameen et al. (2018) and Güllü et al. (2016), where they reported differences in perceptions between countries.

When focusing on gender, males showed higher means than females on all items (except one) and all variables. Also, the ANOVA test on item level yielded more differences than country analysis. This result indicates a stronger discriminatory role played by gender when compared to country influence (similar to the work of Ameen et al. (2018) and Tarhini et al. (2014)). The same can be said on the variable level. When conducting a regression test, both male and female samples yielded equal prediction power, but different significant indicators. The discussion section included more details of the analysis of this study. Following are the results of hypotheses testing in Table 9. 
Table 9. hypotheses testing results

\begin{tabular}{|c|c|c|c|c|c|c|}
\hline \multirow[t]{2}{*}{$\mathbf{H}$} & \multirow[t]{2}{*}{ Predictor } & \multicolumn{2}{|c|}{ Country Factor } & \multicolumn{2}{|c|}{ Gender Factor } & \multirow{2}{*}{$\begin{array}{l}\text { Overal } \\
\text { Sample }\end{array}$} \\
\hline & & Gulf & Jordan & Male & Female & \\
\hline $\mathrm{H} 1$ & Relative Advantage (RA) & $\mathrm{X}$ & $\checkmark$ & $\mathrm{X}$ & $\mathrm{X}$ & $\mathrm{X}$ \\
\hline $\mathrm{H} 2$ & Perceived Enjoyment (PE) & $\checkmark$ & $\checkmark$ & $\mathrm{x}$ & $\checkmark$ & $\checkmark$ \\
\hline H3 & Perceived Creativity (PC) & $\checkmark$ & $\checkmark$ & $\checkmark$ & $\checkmark$ & $\checkmark$ \\
\hline $\mathrm{H} 4$ & Collaboration Gains (CG) & $\checkmark$ & $\checkmark$ & $\checkmark$ & $\checkmark$ & $\checkmark$ \\
\hline
\end{tabular}

\subsection{Contributions and Implications}

Our results include an important contribution to the literature and a confirmation of previous results reported in our background section. Research related to enjoyment was confirmed, where enjoyment was a significant factor associated with FCs (Baytiyeh, 2017; Meyers, 2016). The second factor that was supported by previous research is creativity, where previous work emphasized the role of flipped classrooms in generating opportunities for creativity and innovation (Pan, Nyeu, \& Cheng, 2017), or at least give high performance students the time to generate new ideas (Al-Zahrani, 2015). The final factor that was supported by previous research is the collaboration opportunities between students (or between teachers and students), where the time saved by FCs will open venues for group class work, or open chances to communicate and collaborate more (Balan, Clark, \& Restall, 2015; AlZahrani, 2015; Shu, 2015; Huang et al., 2014). The only result that was not supported by previous research is relative advantage, where previous research emphasized the benefits and values of flipped classrooms (Huang \& Hong, 2015; Hotle \& Garrow, 2016), but only one study reported conflicting results (Koo \& Panahi, 2016).

The results of this study encourage universities to adopt FC method based on the relative advantage of the method. It is also important to address gender-based needs, as it is a significant moderator. Based on our results, we can say that differences attributed to country were not closely related to infrastructure of university support, but the adoption of an instructor. The instructor carried the initiative by himself, where he utilized social media and encouraged his students to watch the videos.

\subsection{Limitations and Future Work}

This study is limited by its sample size and sampling process. The differences in samples (on both gender and country) may have influenced the results. When moving from item level to variable level, and from ANOVA tests to regression tests, the sample size imposed similar results. Still, the contribution of this paper is evidenced based on the size of overall sample and the context of method. The second limitation is the difference in the procedure followed in collecting data. The Gulf sample was collected using a paper-based survey and in a class setup. The Jordanian sample targeted an online group registered for a computer science course and filled in the survey online. Future research can address the bias caused by data collection method by using similar research conditions except for collects method (online vs. paper based).

This study is the first to address students' perceptions toward flipped classrooms in the Gulf area or Jordan. Our results regarding country's influence were not promising when compared to gender (based on ANOVA tests). Based on that further research should be carried to explore the dimensions of each culture and see if our choice of country discrimination is logical. The extensive literature review tried to gather a set of predictors that have an influence on the adoption of FC, and succeeded in doing so based on the bivariate correlations. Still, we can address different issues in future work. The perceptions of instructors might be of a greater importance to practice and the educational industry as they have more control on the decision to adopt the method or not. Instructors 
have the say in implementing the method more than students. The efforts put by universities might yield negative results or go in vain if students do not adopt the method (based on their perceptions of enjoyment and other significant factors).

The Arabic language instrument needs more replication to reach a reliable and valid status, where previous research indicates significant influence of instrument language on research results (Abu-Shanab \& Md Nor, 2013). Finally, other direction of explorations of flipped classrooms can be addressed like the influence of the method on students' personal life and their extra non-curricular activities. 


\section{REFERENCES}

Abu-Shanab, E., \& Al-Tarawneh, H. (2015, April-June). The Influence of Social Networks on High School Students' Performance. International Journal of Web-Based Learning and Teaching Technologies, 10(2), 44-52. doi:10.4018/IJWLTT.2015040104

Abu-Shanab, E., \& Md Nor, K. (2013). The Influence of Language on Research Results. Management Research and Practice Journal, 4(2), 37-48.

Agarwal, P., \& Prasad, J. (1998). A Conceptual and Operational Definition of Personal Innovativeness in the Domain of Information Technology. Information Systems Research, 9(2), 204-217. doi:10.1287/isre.9.2.204

Al-Zahrani, A. (2015). From Passive to Active: The Impact of the Flipped Classroom through Social Learning Platforms on Higher Education Students' Creative Thinking. British Journal of Educational Technology, 46(6), 1133-1148. doi:10.1111/bjet.12353

Alquraan, H., Abu-Shanab, E., Banitaan, S., \& Al-Tarawneh, H. (2017). Motivations for Using Social Media: Comparative Study Based on Cultural Differences between American and Jordanian Students. International Journal of Social Media and Interactive Learning Environments, 5(1), 48-61. doi:10.1504/IJSMILE.2017.086093

Ameen, N., Willis, R., \& Hussain Shah, M. (2018). An examination of the gender gap in smartphone adoption and use in Arab countries: A cross-national study. Computers in Human Behavior, 89, 148-162. doi:10.1016/j. chb.2018.07.045

Arnold-Garza, S. (2014). The flipped Classroom Teaching Model and its Use for Information Literacy Instruction. Communications in Information Literacy, 8(1), 7-22. doi:10.15760/comminfolit.2014.8.1.161

Balan, P., Clark, M., \& Restall, G. (2015). Preparing Students for Flipped or Team-Based Learning Methods. Journal of Education and Learning, 57(6), 639-657.

Baytiyeh, H. (2017). The Flipped Classroom Model: When Technology Enhances Professional Skills. The International Journal of Information and Learning Technology, 34(1), 51-62. doi:10.1108/IJILT-07-2016-0025

Beatty, B., \& Albert, M. (2016). Student Perceptions of a Flipped Classroom Management Course. Journal of Applied Research in Higher Education, 8(3), 316-328. doi:10.1108/JARHE-09-2015-0069

Bhagat, K., Chang, C., \& Chang, C. (2016). The Impact of the flipped Classroom on Mathematics Concept Learning in High School. Journal of Educational Technology \& Society, 13(3), 134-142.

Cohen, J., \& Cohen, P. (1983). Applied Multiple Regression/Correlation Analysis for the Behavioral Sciences. Hillsdale, NJ: Lawrence Erlbaum Associates, Inc.

Cohen, M. (2016). The Flipped Classroom as a Tool for Engaging Discipline Faculty in Collaboration: A Case Study in Library-Business Collaboration. New Review of Academic Librarianship, 22(1), 5-23. doi:10.1080/1 3614533.2015.1073162

Davis, F., Bagozzi, R., \& Warshaw, P. (1992). Extrinsic and intrinsic motivation to use computers in the workplace. Journal of Applied Social Psychology, 22(14), 111-1132. doi:10.1111/j.1559-1816.1992.tb00945.x

Davis, N. (2016). Anatomy of a Flipped Classroom. Journal of Teaching in Travel \& Tourism, 16(3), $228-232$. doi:10.1080/15313220.2015.1136802

Doi, C. (2016). Applying the Flipped Classroom Methodology in a First-Year Undergraduate Music Research Methods Course. Music Reference Services Quarterly, 19(2), 114-135. doi:10.1080/10588167.2016.1167427

El Shamy, N., \& Hassanein, K. (2017). A Meta-Analysis of Enjoyment Effect on Technology Acceptance: The Moderating Role of Technology Conventionality. In Proceedings of the 50th Hawaii International Conference on System Sciences (pp. 4139-4147). Academic press. doi:10.24251/HICSS.2017.501

Foldnes, N. (2016). The Flipped Classroom and Cooperative Learning: Evidence from a Randomized Experiment. Active Learning in Higher Education, 17(1), 39-49. doi:10.1177/1469787415616726

Furumo, K., Hennessey, H., \& Abu-Shanab, E. (2011). Performance and Perceptions Of Slacking In Virtual Cross-Cultural Teams. In Proceedings of the IADIS Multi Conference on Computer Science and Information Systems (MCCSIS 2011). Academic Press. 
Gilboy, B., Heinerichs, S., \& Pazzaglia, G. (2015). Is Flipping Enough? A Mixed Approach to Introductory Information Literacy Instruction. College \& Research Libraries News, 76(1), 10-13. doi:10.5860/crln.76.1.9240

Gubbiyappa, K., Barua, A., Das, B., Murthy, V., \& Baloch, H. (2016). Effectiveness of flipped classroom with Poll Everywhere as a Teaching-Learning Method for Pharmacy Students. Indian Journal of Pharmacology, 48(7), 41-46. doi:10.4103/0253-7613.193313 PMID:28031607

Güllü, F., Kuusik, R., Shogenov, K., Laanpere, M., Oysal, Y., Sözcü, O., \& Parlak, Z. (2016). An Analysis and Comparison of Adoption of E-learning Systems in Higher Education by Lecturers at Largest Universities in Estonia and Turkey. Baltic J. Modern Computing, 4(30), 428-440.

Hair, J., Anderson, R., Tatham, R., \& Black, W. (1998). Multivariate Data Analysis. Upper Saddle River, NJ: Prentice Hall.

Hotle, S., \& Garrow, L. (2016). Effects of the Traditional and Flipped Classrooms on Undergraduate Student Opinions and Success. Journal of Professional Issues in Engineering Education and Practice, 142(1), 1-11. doi:10.1061/(ASCE)EI.1943-5541.0000259

Hsu, S., Chen, C., Chang, W., \& Hu, Y. (2016). An Investigation of the Outcomes of PGY Students' Cognition of and Persistent Behavior in Learning through the Intervention of the Flipped Classroom in Taiwan. PLoS One, 11(12), 1-14. doi:10.1371/journal.pone.0167598 PMID:27911937

Huang, Y., \& Hong, Z. (2015). The Effect of a Flipped English Classroom Intervention on Students' Information and Communication Technology and English Reading Comprehension. Educational Technology Research and Development, 64(2), 175-193. doi:10.1007/s11423-015-9412-7

Huang, Y., Liao, Y., Huang, S., \& Chen, H. (2014). A Jigsaw-based Cooperative Learning Approach to Improve Learning Outcomes for Mobile Situated Learning. Journal of Educational Technology \& Society, 17(1), 128-140.

Jeong, J., Gonzalez-Gomez, D., \& Canada-Canada, F. (2016). Students' Perceptions and Emotions toward Learning in a Flipped General Science Classroom. Journal of Science Education and Technology, 25(5), 747-758. doi:10.1007/s10956-016-9630-8

Koo, C., \& Panahi, L. (2016). Impact of Flipped Classroom Design on student Performance and Perceptions in a Pharmacotherapy Course. American Journal of Pharmaceutical Education, 80(2), 1-9. doi:10.5688/ajpe80233 PMID:27073286

Lai, P. C., \& Ahmad, Z. A. (2014). Perceived Enjoyment of Malaysian consumers' intention to use a single platform E-payment. Paper presented at the International Conference on Liberal Arts \& Social Sciences. Academic Press.

Li, S., Glass, R., \& Records, H. (2008). The Influence of Gender on New Technology Adoption and Use-Mobile Commerce. Journal of Internet Commerce, 7(2), 270-289. doi:10.1080/15332860802067748

Long, T., Logan, J., \& Waugh, M. (2016). Students' Perceptions of the value of using Videos as a Pre-class Learning Experience in the Flipped Classroom. TechTrends, 60(3), 245-252. doi:10.1007/s11528-016-0045-4

Mairura, K. (2016). Relative Advantage as a Determinant of Technology Adoption among Automobile Mechanics in Micro and Small Enterprises in Kenya. IOSR Journal Of Humanities And Social Science, 21(1), 86-92.

Mandari, H., \& Chong, Y. (2018). Gender and Age Differences in Rural Farmers Intention to Use M-Government Services. Electronic Government an International Journal, 14(3), 217-239. doi:10.1504/EG.2018.093406

Marsono. (2016). Blended Cooperative Learning with Nano Lesson Study Model for the Improvement of the Pedagogic and Teaching Innovation of Prospective Teacher. In Proceedings of the International Mechanical Engineering and Engineering Education Conferences IMEEEC.

Meyers, K. (2016). A Course to Promote Informed Selection of an Engineering Major Using a Partially Flipped Classroom Model. Journal of STEM Education, 17(3), 14-21.

Mndzebele, N. (2013, July). The Effects of Relative Advantage, Compatibility and Complexity in the Adoption of EC in the Hotel Industry. International Journal of Computer and Communication Engineering, 2(4), 473-476. doi:10.7763/IJCCE.2013.V2.229

Moran, K., \& Milsom, A. (2015). The Flipped Classroom in Counselor Education. Counselor Education and Supervision, 54(1), 32-43. doi:10.1002/j.1556-6978.2015.00068.x 
Nederveld, A., \& Berge, Z. (2014). Flipped Learning in the Workplace. Journal of Workplace Learning, 27(2), 162-172. doi:10.1108/JWL-06-2014-0044

Nyagorme, P. (2010). E-Learning Adoption and Utilisation: A Comparative Study Of Kenyatta University, Kenya And University Of Cape Coast, Ghana [Thesis]. Kenyatta University, Kenya. Retrieved from https://irlibrary.ku.ac.ke/bitstream/handle/123456789/10960/E-learning\%20adoption\%20andutilisationpdf-sequence=1

Obradovich, A., Canuel, R., \& Duffy, E. (2015). A Survey of Online Library Tutorials: Guiding Instructional Video Creation to Use in Flipped Classrooms. Journal of Academic Librarianship, 41(6), 751-757. doi:10.1016/j. acalib.2015.08.006

Ollermann, F., Rolf, R., Greweling, C., \& Klaben, A. (2017). Principles of Successful Implementation of Lecture Recording in higher Education. Interactive Technology and Smart Education, 14(1), 2-13. doi:10.1108/ITSE09-2016-0031

Pan, H., Nyeu, F., \& Cheng, S. (2017). Leading School for Learning: Principal Practices in Taiwan. Journal of Educational Administration, 55(2), 168-185. doi:10.1108/JEA-06-2016-0069

Rogers, E. (2003). Diffusion of innovation (5th ed.). New York: Free Press.

Rotellar, C., \& Cain, J. (2016). Research, Perspectives, and Recommendations on Implementing the Flipped Classroom. American Journal of Pharmaceutical Education, 80(2), 1-9. doi:10.5688/ajpe80234 PMID:27073287

Shu, X. (2015). An Empirical Study on a Flipped Classroom in Open University Teaching Based on an Ecological Perspective: A Case Study on a Translation Theory and Practice Course. Asian Association of Open Universities Journal, 10(1), 53-63. doi:10.1108/AAOUJ-10-01-2015-B006

Sivapalan, S. (2017). Sustainability, Blended Learning and the Undergraduate Communication Skills Classroom: Negotiating Engineering Undergraduates' Expectations and Perceptions. On the Horizon, 25(1), 7-23. doi:10.1108/OTH-08-2016-0045

Tan, G., \& Ooi, K. (2018). Gender and age: Do they really moderate mobile tourism shopping behavior? Telematics and Informatics, 35(6), 1617-1642. doi:10.1016/j.tele.2018.04.009

Tarhini, A., Hone, K., \& Liu, X. (2014). Measuring the Moderating Effect of Gender and Age on E-Learning Acceptance in England: A Structural Equation Modeling Approach for an Extended Technology Acceptance Mode. Journal of Educational Computing Research, 51(2), 163-184. doi:10.2190/EC.51.2.b

Tolks, D. (2016). An Introduction to the Inverted/Flipped Classroom Model in Education and Advanced Training in Medicine and in the Health Care Profession. GMS Journal for Medical Education, 33(3), 1-11. PMID:27275511

Venkatesh, V., Morris, M., Davis, G., \& Davis, F. (2003). User Acceptance of Information Technology: Toward a Unified View. Management Information Systems Quarterly, 27(3), 425-478. doi:10.2307/30036540

Venkatesh, V., \& Morris, M. G. (2000). Why don't men ever stop to ask for directions? Gender, social influence, and their role in technology acceptance and usage behavior. Management Information Systems Quarterly, 24(1), 115-139. doi:10.2307/3250981

Venkatesh, V., Thong, J., \& Xu, X. (2012). Consumer Acceptance And Use Of Information Technology: Extending The Unified Theory Of Acceptance And Use Of Technology. Management Information Systems Quarterly, 36(1), 157-178. doi:10.2307/41410412

Wang, Y. S., Wu, M. C., \& Wang, H. Y. (2009). Investigating the determinants and age and gender differences in the acceptance of mobile learning. British Journal of Educational Technology, 40(1), 92-118. doi:10.1111/ j.1467-8535.2007.00809.x

Zainuddin, Z., \& Attaran, M. (2016). Malaysian Students' Perceptions of Flipped Classroom: A Case Study. Innovations in Education and Teaching International, 53(6), 660-670. doi:10.1080/14703297.2015.1102079

Zhang, X., \& Xu, J. (2015). Integration of Micro Lectures into the Blended Learning Discourse in Tertiary Education. Asian Association of Open Universities Journal, 10(2), 13-28. doi:10.1108/AAOUJ-10-02-2015-B003

Zhang, Y., Dang, Y., \& Amer, B. (2016). A Large-Scale Blended and Flipped Class: Class Design and Investigation of Factors Influencing Students' Intention to Learn. IEEE Transactions on Education, 59(4), 263-273. doi:10.1109/TE.2016.2535205 


\section{APPENDIX A}

Table 10. Items means and standard deviations based on country

\begin{tabular}{|c|c|c|c|c|}
\hline \multirow[t]{2}{*}{ Item Short Description } & \multicolumn{2}{|c|}{ Gulf Sample } & \multicolumn{2}{|c|}{ Jordan Sample } \\
\hline & Mean & $\begin{array}{l}\text { Std. } \\
\text { Dev. }\end{array}$ & Mean & $\begin{array}{l}\text { Std. } \\
\text { Dev. }\end{array}$ \\
\hline Total construct - Relative Advantage & 3.751 & 0.966 & 3.936 & $\mathbf{0 . 5 8 7}$ \\
\hline Q1: Watching prerecorded videos helps me understand the course material & 3.97 & 1.186 & $4.20 *$ & 0.696 \\
\hline Q2: Using videos enables me to review lectures many times as needed & 4.22 & 1.183 & $4.32 *$ & 0.733 \\
\hline Q3: Using FC reinforce self-dependence skills & 3.75 & 1.149 & $3.90 *$ & 0.801 \\
\hline Q4: Using videos helps me enrich my skills and knowledge & 3.61 & 1.142 & $3.74 *$ & 0.857 \\
\hline Q5: sing FC enriches the discussion in the classroom & $3.55^{*}$ & 1.173 & 3.48 & 0.974 \\
\hline Q6: FC method enables me to manage and organize study time as wanted & 3.42 & 1.387 & $3.91 *$ & 0.876 \\
\hline Total construct - Perceived Enjoyment & 3.68 & 0.88 & 3.854 & 0.558 \\
\hline Q7: I believe that FC is enjoyable & 3.26 & 1.239 & $3.66^{*}$ & 0.901 \\
\hline Q8: I believe that watching videos reduces students' distraction & 3.44 & 1.185 & $3.60 *$ & 1.015 \\
\hline Q9: I believe that watching videos don't wats students' time & 3.30 & 1.274 & $3.47 *$ & 1.039 \\
\hline Q10: I prefer watching short video clips than long ones as they are boring & $4.31 *$ & 1.082 & 4.24 & 0.823 \\
\hline Q11: It is enjoyable to use more than one teaching method & 4.10 & 1.163 & $4.32 *$ & 0.728 \\
\hline Total construct - Perceived Creativity & 3.485 & 0.978 & 3.787 & 0.634 \\
\hline Q12: FC helps me think differently & 3.44 & 1.103 & $3.65^{*}$ & 0.853 \\
\hline Q13: FC helps me build more flexible ideas & 3.47 & 1.048 & $3.70 *$ & 0.904 \\
\hline Q14: FC helps me build applicable ideas & 3.43 & 1.089 & $3.78 *$ & 0.762 \\
\hline Q15: FC helps me build new diverse ideas & 3.45 & 1.115 & $3.68 *$ & 0.815 \\
\hline Q16: FC offers a chance to find innovative solutions for my problems & 3.33 & 1.155 & $3.77 *$ & 0.769 \\
\hline Q17: FC is an innovative method by itself & 3.79 & 1.211 & $4.15^{*}$ & 0.780 \\
\hline Total construct - Collaboration Gains & 3.298 & 0.98 & 3.452 & 0.811 \\
\hline Q18: FC helps me cooperate effectively with my colleagues & 3.28 & 1.198 & $3.39 *$ & 1.027 \\
\hline Q19: FC helps me stay connected with my instructors & 3.47 & 1.109 & $3.63 *$ & 1.033 \\
\hline Q20: FC make communication with my colleagues easier & 3.21 & 1.079 & $3.47 *$ & 0.945 \\
\hline Q21: FC helps me work better in teams & 3.24 & 1.123 & $3.36^{*}$ & 0.944 \\
\hline Total construct - FC Adoption & 3.158 & 1.166 & 3.708 & 0.882 \\
\hline Q22: I recommend that all instructors to use FC & 3.27 & 1.302 & $3.79 *$ & 1.048 \\
\hline Q23: If I have the choice, I will register more courses that use FC & 3.21 & 1.286 & $3.87 *$ & 1.086 \\
\hline Q24: FC method can succeed in all types of courses & 3.00 & 1.278 & $3.39 *$ & 1.154 \\
\hline Q25: I will be happy if instructors use FC always. & 3.16 & 1.345 & $3.79 *$ & 0.949 \\
\hline
\end{tabular}

* Higher (Gulf Vs. Jordan Sample) 


\section{APPENDIX B}

Table 11. ANOVA test comparing the item means (country and gender)

\begin{tabular}{|c|c|c|c|c|}
\hline \multirow[t]{2}{*}{ Item* } & \multicolumn{2}{|c|}{ Gulf vs. Jordan } & \multicolumn{2}{|c|}{ Males vs. Females } \\
\hline & $\mathbf{F}$ & Sig. & $\mathbf{F}$ & Sig. \\
\hline Relative Advantage 1 & 3.665 & 0.056 & 2.499 & 0.115 \\
\hline Relative Advantage 2 & 0.613 & 0.434 & 1.551 & 0.214 \\
\hline Relative Advantage 3 & 1.502 & 0.221 & 3.857 & 0.050 \\
\hline Relative Advantage 4 & 1.121 & 0.291 & 5.041 & 0.025 \\
\hline Relative Advantage 5 & 0.231 & 0.631 & 0.187 & 0.666 \\
\hline Relative Advantage 6 & 11.695 & 0.001 & 5.748 & 0.017 \\
\hline Perceived Enjoyment 1 & 9.191 & 0.003 & 8.694 & 0.003 \\
\hline Perceived Enjoyment 2 & 1.429 & 0.233 & 0.099 & 0.753 \\
\hline Perceived Enjoyment 3 & 1.567 & 0.212 & 1.959 & 0.163 \\
\hline Perceived Enjoyment 4 & 0.32 & 0.572 & 0.139 & 0.710 \\
\hline Perceived Enjoyment 5 & 3.369 & 0.067 & 3.977 & 0.047 \\
\hline Perceived Creativity 1 & 3.211 & 0.074 & 5.230 & 0.023 \\
\hline Perceived Creativity 2 & 3.839 & 0.051 & 3.639 & 0.057 \\
\hline Perceived Creativity 3 & 9.013 & 0.003 & 13.273 & 0.000 \\
\hline Perceived Creativity 4 & 3.406 & 0.066 & 5.664 & 0.018 \\
\hline Perceived Creativity 5 & 12.449 & 0.000 & 11.973 & 0.001 \\
\hline Perceived Creativity 6 & 7.531 & 0.006 & 9.736 & 0.002 \\
\hline Collaboration Gains 1 & 0.739 & 0.391 & 4.469 & 0.035 \\
\hline Collaboration Gains 2 & 1.497 & 0.222 & 4.815 & 0.029 \\
\hline Collaboration Gains 3 & 4.44 & 0.036 & 11.719 & 0.001 \\
\hline Collaboration Gains 4 & 0.869 & 0.352 & 5.527 & 0.019 \\
\hline FC Adoption 1 & 13.07 & 0.000 & 15.759 & 0.000 \\
\hline FC Adoption 2 & 20.551 & 0.000 & 8.245 & 0.004 \\
\hline FC Adoption 3 & 7.039 & 0.008 & 7.368 & 0.007 \\
\hline FC Adoption 4 & 19.283 & 0.000 & 9.173 & 0.003 \\
\hline
\end{tabular}

* For item description, please refer to Appendix A 


\section{APPENDIX C}

Table 12. Items means and standard deviations based on gender

\begin{tabular}{|c|c|c|c|c|}
\hline \multirow[b]{2}{*}{ Item Short Description } & \multicolumn{2}{|c|}{ Male } & \multicolumn{2}{|c|}{ Females } \\
\hline & Mean & $\begin{array}{l}\text { Std. } \\
\text { Dev. }\end{array}$ & Mean & $\begin{array}{l}\text { Std. } \\
\text { Dev. }\end{array}$ \\
\hline Q1: Watching prerecorded videos helps me understand the course material & $4.19 *$ & 0.907 & 3.99 & 1.075 \\
\hline Q2: Using videos enables me to review lectures many times as needed & $4.37 *$ & 0.900 & 4.21 & 1.082 \\
\hline Q3: Using FC reinforce self-dependence skills & $3.97 *$ & 0.944 & 3.72 & 1.055 \\
\hline Q4: Using videos helps me enrich my skills and knowledge & $3.85 *$ & 0.945 & 3.57 & 1.071 \\
\hline Q5: sing FC enriches the discussion in the classroom & $3.56^{*}$ & 1.026 & 3.50 & 1.129 \\
\hline Q6: FC method enables me to manage and organize study time as wanted & $3.84 *$ & 1.055 & 3.48 & 1.308 \\
\hline Total construct - Relative Advantage & 3.965 & 0.719 & 3.750 & 0.879 \\
\hline Q7: I believe that FC is enjoyable & $3.67 *$ & 1.005 & 3.26 & 1.180 \\
\hline Q8: I believe that watching videos reduces students' distraction & $3.52 *$ & 1.138 & 3.47 & 1.133 \\
\hline Q9: I believe that watching videos don't wats students' time & $3.50 *$ & 1.134 & 3.29 & 1.224 \\
\hline Q10: I prefer watching short video clips than long ones as they are boring & 4.27 & 0.906 & $4.31 *$ & 1.015 \\
\hline Q11: It is enjoyable to use more than one teaching method & $4.35^{*}$ & 0.855 & 4.10 & 1.099 \\
\hline Total construct - Perceived Enjoyment & 3.856 & 0.694 & 3.687 & 0.815 \\
\hline Q12: FC helps me think differently & $3.71 *$ & 0.988 & 3.42 & 1.032 \\
\hline Q13: FC helps me build more flexible ideas & $3.71 *$ & 1.054 & 3.48 & 0.974 \\
\hline Q14: FC helps me build applicable ideas & $3.85 *$ & 0.915 & 3.41 & 1.011 \\
\hline Q15: FC helps me build new diverse ideas & $3.73 *$ & 1.028 & 3.43 & 1.015 \\
\hline Q16: FC offers a chance to find innovative solutions for my problems & $3.79 *$ & 0.960 & 3.34 & 1.069 \\
\hline Q17: FC is an innovative method by itself & $4.22 *$ & 0.858 & 3.80 & 1.148 \\
\hline Total construct - Perceived Creativity & 3.826 & 0.791 & 3.484 & 0.898 \\
\hline Q18: FC helps me cooperate effectively with my colleagues & $3.52 *$ & 1.100 & 3.22 & 1.152 \\
\hline Q19: FC helps me stay connected with my instructors & $3.73 *$ & 1.007 & 3.43 & 1.116 \\
\hline Q20: FC make communication with my colleagues easier & $3.59 *$ & 0.989 & 3.15 & 1.042 \\
\hline Q21: FC helps me work better in teams & $3.48 *$ & 0.993 & 3.17 & 1.085 \\
\hline Total construct - Collaboration Gains & 3.568 & $\mathbf{0 . 8 0 7}$ & 3.245 & 0.961 \\
\hline Q22: I recommend that all instructors to use FC & $3.85^{*}$ & 1.091 & 3.26 & 1.264 \\
\hline Q23: If I have the choice, I will register more courses that use FC & $3.74 *$ & 1.160 & 3.30 & 1.286 \\
\hline Q24: FC method can succeed in all types of courses & $3.41 *$ & 1.253 & 2.99 & 1.231 \\
\hline Q25: I will be happy if instructors use FC always. & $3.70 *$ & 1.130 & 3.23 & 1.287 \\
\hline Total construct - FC Adoption & 3.666 & 0.992 & 3.204 & 1.126 \\
\hline
\end{tabular}

*Higher means (Male Vs. Female Sample) 

- Carbondale, USA, his MBA from Wilfrid Laurier University in Canada, and his bachelor's in civil engineering from Yarmouk University (YU) in Jordan. His research interest in areas like E-government, technology acceptance, E-marketing, E-CRM, digital divide, e-CRM, IT project management, and e-learning. Published many articles in journals and conferences, and authored three books in e-government, and few book chapters. Dr. Abu-Shanab worked as an assistant dean for students' affairs, quality assurance officer in Oman, and the director of Faculty Development Center at YU. He is an associate professor in the MIS Department and was the department chair. Now Dr. Abu-Shanab works at Qatar University in the accounting and Information Systems Department. 